\title{
Capturing value from business models: the role of formal and informal protection strategies
}

\author{
Amir Bonakdar* \\ Center for Design Research, \\ Stanford University, \\ 424 Panama Mall, Bldg 560, Stanford, 94305-2232, USA \\ Email: bonakdar@stanford.edu \\ *Corresponding author
}

\section{Karolin Frankenberger}

Institute of Technology Management,

University of St.Gallen,

Dufourstrasse 40a, 9000 St.Gallen, Switzerland

Email: karolin.frankenberger@unisg.ch

\author{
Martin A. Bader \\ THI Business School, \\ Technische Hochschule Ingolstadt, \\ Esplanade 10, 85049 Ingolstadt, Germany \\ Email: martin.bader@thi.de
}

\section{Oliver Gassmann}

Institute of Technology Management,

University of St.Gallen,

Dufourstrasse 40a, 9000 St.Gallen, Switzerland

Email: oliver.gassmann@unisg.ch

\begin{abstract}
As an overarching concept a business model describes how a firm creates and captures value for itself, its customers, and its partners. Although research has highlighted the importance of value creation and capture of business models, it primarily focused on the value creation mechanisms and neglected aspects of value capturing: Until to date, little is known about how firms attempt to protect their business models from competition, which is a critical component of value capture. Drawing on a sample of 24 cases, we explore how business models relate to IP protection mechanisms for value capture and derive a business model protection framework. Our empirical study reveals that the choice of IP protection is contingent on the applied business model. Whereas some razor and blade business models are characterised by a high degree of both formal and informal protection, firms operating franchising business models put higher emphasis on informal protection strategies. Firms running the pay-per-use business model or the multi-sided platform business model apply formal and informal protection strategies to a medium degree in order to capture value. Our findings extend business model literature on novel
\end{abstract}


insights on intellectual property management and also extend the "profiting from innovation literature' on protection mechanisms in the context of business models.

Keywords: business model; business model innovation; intellectual property; strategy; innovation; value capture.

Reference to this paper should be made as follows: Bonakdar, A., Frankenberger, K., Bader, M.A. and Gassmann, O. (2017) 'Capturing value from business models: the role of formal and informal protection strategies', Int. J. Technology Management, Vol. 73, No. 4, pp.151-175.

Biographical notes: Amir Bonakdar is a Postdoctoral Scholar at the Center for Design Research at Stanford University. He also heads the Business Design Research group at Stanford and the University of St. Gallen, Switzerland. Amir's primary research interests focus on business model design, protection, and the anchoring of business model innovation teams within organisations. $\mathrm{He}$ worked for several years for SAP as a consultant and researcher helping various clients in business process and business model innovations. He is an active speaker in Executive MBA programs and received his $\mathrm{PhD}$ in Management with specialisation in Business Innovation from the University of St. Gallen, Switzerland.

Karolin Frankenberger is an Assistant Professor at the Institute of Technology Management, University of St. Gallen, Switzerland. After completing her PhD in 2004, she was working for several years as a consultant at McKinsey and Company, helping various clients in topics such as business model innovation and strategic change. Her research has been published in the Academy of Management Journal and she has been awarded with the 'Sumantra Ghoshal Research and Practice Award' and the 'Distinguished Paper Award' of the Business Policy and Strategy Division at the 2006 Annual Meeting of the Academy of Management. Her current research interests include business model innovation, imitation, strategic networks, and strategic initiatives.

Martin A. Bader is a Professor of Technology Management and Entrepreneurship at the THI Business School of Technische Hochschule Ingolstadt, Germany. He is also a European and Swiss Patent Attorney and managing partner of the innovation and IP management advisory group BGW AG, Switzerland. Since 2014, he is a mediator for the WIPO Arbitration and Mediation Center. In 2013, he was selected as one of the world's leading IP strategists by IAM Strategy 300 . He previously worked as the Vice President and Chief Intellectual Property Counsel at Infineon Technologies in Munich, Germany.

Oliver Gassmann is Professor of Technology Management at the University of St. Gallen, Switzerland and Director of the institute. After completing his $\mathrm{PhD}$ in 1996, he was leading research and advanced development of Schindler Corporation, headquartered in Ebikon, Switzerland. He published in leading journals such as Research Policy, R\&D Management, Journal of Management, Journal of World Business, International Journal of TechnologyManagement, IEEE Transactions on Engineering Management and Harvard Business Manager. His research focuses on the question of how companies innovate and achieve competitive advantage from innovation.

This paper is a revised and expanded version of a paper entitled 'Business model innovation and intellectual property management' presented at Annual Meeting of the Academy of Management, Orlando, Florida, 9-13 August 2013. 


\section{Introduction}

In recent years business models have attracted increasing attention among both researchers and practitioners (Baden-Fuller and Morgan, 2010; Chesbrough, 2007; DaSilva and Trkman, 2014; McGrath, 2010; Zott et al., 2011). Although several definitions of the term business model exist, researchers agree that a business model expresses the underlying logic of a firm's business (Teece, 2010; Zott et al., 2011). In previous business model literature, aspects of value creation, delivery, and capture have been highlighted as being especially important (Björkdahl, 2009; Magretta, 2002; Shafer et al., 2005; Teece, 2010).

In the past however most literature has primarily focused on the value creation and delivery mechanisms of business models. Mechanisms for value capturing or value appropriation have been widely neglected (Desyllas and Sako, 2013) - which is surprising given that business models themselves, are becoming an increasingly important part of firms' intellectual property (IP) (Desyllas and Sako, 2013; Rappa, 2001; Rivette and Kline, 2000; Zott et al., 2011). Similar to any other new technology, product, or service, business models need to be protected. IP protection strategies act as one instrument of value capture and have been mainly discussed in the profiting from innovation' literature stream (Teece, 1986, 2006). However, they primarily focus on technological, product and process innovations.

One exception is a study by Desyllas and Sako (2013), which examined how IP strategies help to capture value from business model innovation. The authors found that formal IP protection (patents and trademarks) and strategic protection (specialised complementary assets) are complementary: whereas formal IP protection is especially useful in the early stages of business model innovation, strategic protection helps ensure long-term competitiveness. However, important questions are still unanswered. For example, are different business models also associated with different strategies for value capture? Do different configurations of formal and informal protection fit certain business models better than others?

This paper aims to clarify these questions by investigating different forms of formal and informal protection strategies across four different types of business models: the franchising model, the razor and blade model, the pay-per-use model, and the multi-sided platform model. Our purpose is to explain how and why different business models influence the relationship between formal and informal protection strategies and value appropriation. In a sample of 24 cases we analyse how firms that successfully apply these business models protect their businesses with formal and informal protection strategies. Subsequently, we derive a business model protection framework for the analysis of IP protection strategies contingent on the application of specific business models. Our findings suggest that the logic of different business models calls for different configurations of formal and informal protection to capture value.

This paper contributes to the literature on business models by extending it to elements of IP Management and highlighting the value capture mechanisms contingent on different business models. The paper is structured as follows: Section 2 provides the theoretical background for our analysis by presenting the four examined business models as mentioned above as well as IP protection strategies (formal, informal); Section 3 portrays the empirical setup of the study by illustrating 24 cases and provides details on the methodology conducted for case analysis and the development of the protection 
framework; finally in the fourth section we present and discuss the results of our undertaking. The business model protection framework is outlined, which categorises our sample based on the degree of formal and informal protection. Building on the business model protection framework we subsequently develop four propositions. The contribution closes by discussing the implications for theory and practice as well as the limitations of the study, and suggests paths for future research.

\section{Theoretical background}

This section analyses in depth the theoretical background necessary for our line of reasoning, namely literature on business models and IP protection strategies.

\subsection{Business models}

The business model construct has received growing attention over recent years in both literature and management practice. The business model represents a holistic concept that reflects the different components a business comprises and describes how these components are interlinked in order to create value within the business ecosystem and to capture parts of it for the focal firm (Amit and Zott, 2001; Baden-Fuller et al., 2010; Baden-Fuller and Mangematin, 2013; Chesbrough and Rosenbloom, 2002; McGrath, 2010).

The three components which are named most often as the key elements of a business model are the customer value proposition, internal processes, and the revenue model (Baden-Fuller et al., 2010; Doganova and Eyquem-Renault, 2009; Magretta, 2002; Teece, 2010). The first dimension describes the value offering to the target customer or customer segment (Baden-Fuller and Mangematin, 2013; Demil and Lecocq, 2010; Teece, 2010), the second dimension refers to the underlying processes and activities, as well as the involved internal resources and external partners (Chesbrough and Rosenbloom, 2002; Zott and Amit, 2007, 2008) and the third dimension explains how the firm realises revenues and profits out of the prior two dimensions (Casadesus-Masanell and $\mathrm{Zhu}$, 2010; 2013; Chesbrough and Rosenbloom, 2002). Scholars agree that firm internal processes have to be matched with outside elements that include the customer side and explain how to monetise the created value (Baden-Fuller and Mangematin, 2013; Amit and Zott, 2001; Teece, 2010). Therefore, business models are recognised as describing how firms create, deliver and at the same time capture value for both themselves and their stakeholders in their business ecosystem (Zott et al., 2011).

Most prior research has focused on the value creation and delivery elements of business models (Björkdahl, 2009; Chesbrough and Rosenbloom, 2002; Klang et al., 2014; Morris et al.,2005; Teece, 2010). For example, Amit and Zott (2001) and Zott and Amit (2013) identify four sources of value creation: efficiency (anchored in transaction cost economics), lock-in (inherent in strategic networks), complementarities (anchored in resource-based theory), and novelty (through Schumpeterian innovation).

The issue of value capture has remained relatively underexplored. However, it is fundamental to the profitability of firms (Lepak et al., 2007; Priem, 2007), and is especially important in the realm of business models for two main reasons. First, business models are increasingly becoming part of firms' intellectual property and thus need to be protected. Second, as the locus of value creation of business models often spans firm and 
industry boundaries (Amit and Zott, 2001), it becomes crucial to understand the mechanism by which to capture value for the individual firm.

Recent studies have started to address this interesting topic. Casadesus-Masanell and Zhu (2013) analyse the relationship between business model innovation and imitation. They argue that entrants with new business models need to decide whether to reveal their innovation, thus facing the risk that incumbents adapt the business model - or to hide it by adopting conventional business models. Whereas their study focuses on strategic interactions between different market players, Desyllas and Sako (2013) go one step further and explicitly address the topic of business model protection. Based on the profiting from innovation framework (Chesbrough et al., 2006; Teece, 1986; 2006), they show that formal IP protection methods and strategic ones complement one another. Whereas formal IP rights are useful as short-term defensive strategies, long-term value capture can only be ensured by strengthening specialised complementary assets.

Due to the complexity and wide variety of business models currently employed by firms, many researchers have focused on a specific subset of business models in order to ease the analysis. For example Casadesus-Masanell and Zhu (2013) focus on business models that allow the firm to monetise its products through sponsors, and Desyllas and Sako, (2013) focus on the pay-as-you-drive business model in the insurance industry. In this paper, we will portray the franchising, the razor and blade, the pay-per-use and the multi-sided platform business models. We do not claim that these four business models represent a complete typology of all business models that firms could possibly run. Rather our intention is to understand how specific business models are characterised by formal and informal protection strategies and, in line with the studies mentioned above, exemplify this on the basis of a subset of well-known ones. We selected these four business models for the following: first, they have been the focus of various research endeavors in the past (Caves and Murphy, 1976; Hagiu, 2009; Johnson, 2010; Norton, 1988; Postmus et al., 2009; Teece, 2010;); second, they are well-known in management practice (Brickley and Dark, 1987; Eisenmann et al., 2006; Jiang et al., 2007; Johnson, 2010); and third, they are applicable in different industries (Evans, 2003; Kim, 2005; Lafontaine, 1992; McGrath, 2010; Rochet and Tirole, 2003).

Franchising: The franchising business model describes the business logic, "in which the owner of a protected trade-mark grants to another person or firm, for some consideration, the right to operate under this trademark for the purpose of producing or distributing a product or service" [Caves and Murphy, (1976), p.572]. Thereby the franchisor has the authority to monitor the franchisee for product/service quality and the maintenance of the trademark (Brickley and Dark, 1987; Norton, 1988). The franchisee operates for his own account but is often obliged to pay royalties to the franchisor, e.g., with a share of his sales, or a share of the purchases that have to be made from the franchisor (Lafontaine, 1992). Successful franchising firms are found in various industries such as fashion (Tom Tailor), fast food (McDonalds), and grocery (avec).

Razor and Blade: The razor and blade business model follows a cross-subsidisation logic. Companies operating this model give certain components of their business away for free or sell it below market price in order to generate high margins on the complementary products, which are aggressively marked up (Johnson, 2010; McGrath, 2010; Teece, 2010). To benefit from this business model as a company, it is necessary to create exit barriers for customers and to protect the complementary products from competition and especially imitation. Prominent examples for a successful application of 
the razor and blade model are the razor firms like Gillette who sell the blades for a high price or the ink-jet printer manufacturers like HP who sell the printers relatively low priced and generate high profits with the frequently repurchased cartridges.

Multi-sided platform: In this business model at least two distinct groups of users interact on the platform of a third party (Hagiu, 2009). These user groups are affected by indirect network effects, which means that the attractiveness of the platform increases for one group of users as more members of the other group join - and vice-versa (Evans, 2003). Put differently, the "platform's value to any given user largely depends on the number of users on the network's other side" [Eisenmann et al., (2006), p.2]. In order to bring a multi-sided platform to life, a key challenge for the platform owner is to deal with the 'chicken and egg problem' and to ensure getting both parties 'on board' (Rochet and Tirole, 2003). Successful examples of firms running the multi-sided platform business model are credit card companies like VISA, which connect shoppers with retailers and subsidise the credit card holders. Another example is that of gaming companies, like Nintendo, which act as multisided platforms since they connect game developers with game players.

Pay-per-use: Companies running the pay-per-use business model differ from others by billing the customer solely based on usage (Postmus et al., 2009). Thereby, customers are neither confronted with initial up-front costs, nor do they pay any fixed fees periodically (Jiang et al., 2007). They are only charged variably based on their actual usage (Kim, 2005). The vendor takes a risk and sets aside one pricing option - namely the basic fee in the hope of earning higher profits by charging variably per use. Examples of successful firms operating the pay-per-use business model are found in the video on demand industry (Swisscom, Deutsche Telekom, Cablecom etc.), which offer customers an online video library and charge a certain amount at the end of the month per movie viewed. Another example is illustrated by the pay-per-click model in the field of online marketing. Advertisers do not pay for advertisements as such, but are charged based on how often it is clicked by the internet users. This model is the most dominant online advertising concept and is offered by companies such as Google, Microsoft Bing and Yahoo.

\subsection{IP protection strategies}

As mentioned above, mechanisms for value capture have been neglected in the business model literature. One aspect of capturing value from new business models is the use of IP protection strategies to protect the business model from imitation and value slippage. The protection of IP is much debated in the economic context by various researchers with a focus on product and process innovation (Cohen et al., 2000; Dosi et al., 2006; Harabi, 1995). Teece, $(1986$; 2006) was the first to examine the mechanisms of value capture in the context of innovation. In his groundbreaking and highly influential work, he suggests that capturing value (e.g., profits) from an innovation is highly contingent on the appropriability regime surrounding the innovator. Specifically, it depends on the efficacy of formal (e.g., patents, copyrights) and informal (e.g., trade secrets) IP protection, as well as the type of technology (e.g., product, process, tacit, codified). However, he explained the value capturing mechanisms only in the context of technological innovation. Subsequent researchers broadened the context and also included product and process innovation. For example Amara et al., (2008) investigate how knowledgeintensive business service firms protect their inventions and find that informal as well as 
formal protection strategies are jointly used. Furthermore, they find that the mechanisms of formal and informal IP protection are characterised by a strong interdependency and mutual reinforcement so that innovations are protected from imitations by rivals. In general, the findings outline that formal and informal protection mechanism complement one another, and that both are critical for capturing value from innovation (Arora and Ceccagnoli, 2006; Cohen et al., 2000; Dosi et al., 2006; Hall and Ziedonis, 2001; McGahan and Silverman, 2006; Pisano, 2006).

While almost all researchers in this field distinguish between formal and informal protection strategies, the majority have so far limited their research on patenting and secrecy strategies thereby ignoring other forms of formal and informal protection strategies (Anton and Yao, 2004; Arundel, 2001; Hussinger, 2006). Gallié and Legros (2012) are one of the exceptions. They distinguish between seven forms of formal and informal protection strategies and show with a sample of French firms that the choice of protection strategy depends on various factors such as the type of innovation, the size and market share of the firm, and the firm's R\&D activities. They distinguish between the following protection strategies: patents, design rights, trademarks and copyrights as formal protection strategies and trade secrets, complexity of products and manufacturing process, and lead-time advantage as informal protection mechanism. More specifically, they define the mechanisms as follows:

- $\quad$ Formal IP strategies

1 Patents: an inventor, who registers a patent, receives the right to prohibit the imitation or use (own use or selling it) of his invention by others for a limited time. This allows the inventor to realise monopolistic prices when exploiting the innovation. However when registering a patent the inventor must disclose the information around the innovation and hence enables competitors to 'invent around' the patent. This drawback could overshadow the benefits of realising monopolistic prices for the innovation.

2 Design rights: design rights protect the visual appearance of objects such as the shape, the colours, and the materials. In order to register a design two requirements have to be fulfilled. First, it has to be new, which means that no identical design was published prior to registration. Second, it has to be unique, which means that the overall appearance must differ from other designs.

3 Trademarks: a trademark is a sign, a symbol, a design or expression that distinguishes products or services of a company from the ones of other companies. Although a trademark is not limited in time, the registering company needs to periodically renew it.

4 Copyrights: a firm which registers a copyright receives exclusive rights for an original work and hence obtains the power to determine who may financially benefit from it.

- Informal IP strategies

1 Trade secrets: trade secrets cover non-public information and enable firms to obtain competitive advantage over companies that do not own the information. This includes formulas, methods, techniques, processes, instruments. Firms have to take action to maintain secrecy about the information. 
2 Complexity of products and manufacturing processes: the complexity of products and manufacturing processes depicts an instrument to capture value from innovation. If a product or service consists of complex processes, technologies or components that are necessary to build and distribute it, this complexity grants the firm a competitive advantage, since the offerings are more difficult to imitate.

3 Lead-time advantage: in this context, lead-time advantage is established if firms innovate faster than their competitors. This leads to competitive advantages that enable them to capture value from their innovation.

In this paper we build on this study and include the seven identified mechanisms. This allows us to embrace the most comprehensive set of IP strategies found in past empirical studies as a starting point of our study and to fully understand their influence on value capture for different business models.

\section{Methodology}

\subsection{Case study approach}

As the previous sections describe, the interdependencies between IP protection strategies and business models is a so far understudied area with potentially high theoretical and practical relevance. The value capture mechanisms of business models from an IP perspective have rarely been studied nor conceptualised. Therefore, we addressed this issue using an inductive multiple case study approach (Eisenhardt, 1989; Yin, 2003). To comply with our aims - namely to explore the role of formal and informal IP strategies for value appropriation across four specific business models - we employed a purposeful sampling procedure, which in comparison with selecting cases randomly, allowed us to access information-rich cases from which we could discover "a great deal about issues of central importance to the purpose of the evaluation" [Patton, (1987), p.52].

The cases were selected using the following criteria: First, the case sample must consist of firms with a business model that falls within one of our four investigated classes, namely the franchise model, the razor and blade model, the paper-per-use model, or the multi-sided platform model. Whereas assignment of a case to the franchise model was relatively straightforward, a case was assigned to the razor and blade model if the case firm attracted customers with a low-priced product that subsequently required repeated purchase of high margined complementary products. Firms were assigned to the pay-per-use model if they billed their customers solely based on usage with no fixed fees (either periodically or per item), but only charged based on the actual usage of the firm's offering. Finally, assignment to the multi-sided platform business model required that the firm connected at least two distinct groups of users to interact on their platform. Next, the overall composition of companies in each business model should be as broad as possible - in terms of both industry and field of business. In this way we aimed to maximise the generalisability of our results from each business model. Consequently, we included six companies per business model into the research sample, most of which operated in different industries. Finally, the selected companies should be successful with their business model, especially in terms of value appropriation (i.e., they should earn substantial revenues and make profit using the assigned business model. 
We identified 24 cases that met these criteria. We chose six firms per business model. The identified firms are mostly market leaders in their industry and therefore represent 'typical cases' (Miles and Huberman, 1994) for each business model. The following list describes our research sample:

Table 1 Research sample and case description

\begin{tabular}{|c|c|}
\hline Case & Business model, business description \\
\hline 1 Fast food & Business model: franchising \\
\hline & $\begin{array}{l}\text { Description: as a large multinational restaurant chain, this company focuses on } \\
\text { serving fast food meals such as hamburgers, french fries and soft drinks. The } \\
\text { individual restaurants are operated by franchisees who receive all the necessary } \\
\text { ingredients and equipment to run their business. In return for using the } \\
\text { company's trademark and know-how, franchisees are required to pay part of } \\
\text { their revenue as a royalty fee to the franchiser. }\end{array}$ \\
\hline
\end{tabular}

2 Elderly care Business model: franchising

Description: in order to support aging in place, this company provides nonmedical in-home care for seniors. Its concept of elderly care can easily be transferred to locations in need of such services by allowing franchisees to adapt the company's business model. The company generates revenues with franchising fees.

3 Fashion Business model: franchising

Description: this clothing company provides apparel and fashion accessories for men and women. As a franchisor, it allows entrepreneurs to open new stores under its brand name. The company is compensated by receiving a fee from its franchisees.

4 Restaurant Business model: franchising

Description: in contrast to fast food franchises, this restaurant chain offers fresh and house-made Italian dishes that are cooked individually according to customer preferences. The concept was adopted in more than 70 locations around the world. It's intended to grow even further by allowing franchisees to open new restaurants.

5 Grocery Business model: franchising

Description: this retail company is based in Switzerland and offers a broad variety of consumer goods. Franchisees are authorised to use the company's business model and open their own store. In return, franchisees are obliged to pay a royalty fee based on their revenues.

6 Association Business model: franchising

Description: as a national franchising association, this organisation aims at supporting franchisors and franchisees in their respective domain. After these firms applied for membership, their business models will be screened. When accepted, they're required to pay a small fee and are then granted access to the services provided by the franchising association.

7 Safety Business model: razor and blades

razors Description: being a well-renowned corporation in the personal care industry, this company is specialised in commercialising safety razors for men. It sells both razors and razor blades. Whereas the razors are typically offered at a relatively low price, the razor blades are priced much higher. In essence, most of the revenue is generated by the sales of complementary products. 
Table 1 Research sample and case description (continued)

\begin{tabular}{ll}
\hline Case & \multicolumn{1}{c}{ Business model, business description } \\
\hline $8 \quad \begin{array}{l}\text { Printing } \\
\text { devices }\end{array}$ & $\begin{array}{l}\text { Business model: razor and blades } \\
\text { Description: this American multinational company is one of world's leading } \\
\text { technology corporations. Amongst other products, it supplies a broad variety of } \\
\text { printing devices. Thereof, the prices of ink-jets printers are proportionately low. }\end{array}$ \\
& $\begin{array}{l}\text { Profit arises primarily from the sales of repurchased cartridges. } \\
\text { Coffee } \\
\text { capsules }\end{array}$ \\
& $\begin{array}{l}\text { Business model: razor and blades } \\
\text { Description: the market for coffee is generally highly competitive. This } \\
\text { company was one of the first corporations to offer its coffee pre-apportioned in } \\
\text { capsules. In comparison to conventional coffee, the capsules allowed for much } \\
\text { higher profit margins. This way, the coffee machines could be subsidised and } \\
\text { sold at lower prices in order to attract potential customers. }\end{array}$
\end{tabular}

10 Tooth care Business model: razor and blades

Description: this company is a leading supplier of dental hygiene products such as toothbrushes, dental floss or dental sticks. Most of the company's revenue is not generated by its electrical toothbrushes, but by the toothbrush heads. These toothbrush heads need to be replaced regularly and thus lead to a steady income stream.

11 Electronics Business model: razor and blades

Description: the increasing popularity of e-books led one of the largest electronic commerce corporations to adapt the concept of 'razor \& blades'. The company offers its e-book readers at a comparably low price. Profit is primarily generated with e-books that can be downloaded and installed on the reader.

12 Music Business model: razor and blades

Description: for many decades, this company was predominantly present in the software and hardware industry. It recently launched a platform for distributing music online. The company's mp3-players are sold at moderate prices. The songs, which can be downloaded from the online platform for a small fee, complement the revenues generated by the sales of hardware.

13 Car sharing Business model: pay-per-use

Description: the purchase of a new car is generally associated with significant expenses for the customer. To ease financial hurdles in the private transportation industry, this company provides a car sharing service. Customers can use the company's cars and are charged based on the usage of the vehicles.

14 Online Business model: pay-per-use

marketing Description: this company provides advertising services on the internet. Firms can sign up on the website and start a campaign. Compared to other means for advertising, they pay per click. Hence, firms are only charged for ads that were actually successful in attracting new customers.

15 Healthcare Business model: pay-per-use

Description: being one of world's leading electronics company in the world, this multinational corporation launched a pay-per-use service in order to support firms in the healthcare industry. Based on its vast experience, the corporation is able to provide business assessments and technology recommendations. These healthcare solutions are charged on a pay-per-use basis. 
Table 1 Research sample and case description (continued)

\begin{tabular}{|c|c|c|}
\hline Cas & & Business model, business description \\
\hline \multirow{2}{*}{\multicolumn{2}{|c|}{16 Telco }} & Business model: pay-per-use \\
\hline & & $\begin{array}{l}\text { Description:this company is major telecommunications provider in } \\
\text { Switzerland. It recently launched a cloud computing service on its website, } \\
\text { allowing customers to store their files online while being billed on a pay-per- } \\
\text { use basis. }\end{array}$ \\
\hline \multirow[t]{2}{*}{17} & Video on & Business model: pay-per-use \\
\hline & & $\begin{array}{l}\text { Description: as one of Germany's leading television stations, this company } \\
\text { introduced a video on demand service to complement its traditional TV } \\
\text { broadcasting. Based on the pay-per-use concept, customers are only charged for } \\
\text { movies they actually watch. }\end{array}$ \\
\hline
\end{tabular}

18 Hotel Business model: pay-per-use

Description: whereas many holiday accommodations only provide conventional television, this hotel offers its customers a video on demand service. All rooms are equipped with a flatscreen TVs allowing guests to choose from a broad variety of movies and series. These movies are accessible for a small fee that will be billed at the end of the stay.

19 Gaming Business model: multisided platform

Description: this company is a multinational manufacturer of consumer electronics, most notably known for its video game consoles. Its business model benefits as the number of gamers and video game publishers increase. With more available video games, the console becomes more appealing to gamers. On the other hand, a console with a high player base is profitable for video game publishers and thus entails the production of more video games.

20 Newspaper Business model: multisided platform

Description: by offering a daily newspaper for free, this company created a multisided platform in the publishing industry. With an increasing readership, the newspaper becomes more attracting for advertisers. This enables the company to generate more revenue and potentially provide better content which - in turn - can lead to a larger readership.

21 Couponing Business model: multisided platform

Description: this company's business model is based on a website providing customers the opportunity to buy products at highly discounted prices. The products are sold by companies who are interested in using this multisided platform for customer acquisition. This creates a win-win-situation for all parties involved.

22 Couponing Business model: multisided platform

Description: hosting one of world's leading couponing website, this company offers products and services at much lower prices than they would usually be available. While this is an effective way for companies to commercialise their products, customers profit from lower expenses. The couponing website on the other hand receives a premium for featuring other company's products.

23 Credit card Business model: multisided platform

Description: as a large multinational financial services corporation, this company is best known for offering electronic funds transfers via credit and debit card. As a multisided platform, it helps other companies and its customers to process their payment transactions. 
Table 1 Research sample and case description (continued)

\begin{tabular}{ll}
\hline Case & \multicolumn{1}{c}{ Business model, business description } \\
\hline 24 Online & Business model: multisided platform \\
payments & $\begin{array}{l}\text { Description: this company provides payment and money transfers on the } \\
\text { internet. It facilitates financial transactions for both companies and customers } \\
\text { by offering an alternative to traditional payment methods. Profit arises from } \\
\text { fees on every payment made. }\end{array}$ \\
\hline
\end{tabular}

\subsection{Data collection}

We collected data from three sources. First, we interviewed a total of 24 (senior) managers from the respective firms. The experts contacted should have deep insights into the area of interest in order to be able to structure the concrete field of action logically and precisely. Consequently, we identified interviewees who held management positions in their respective firms and whose daily business is located between management and strategy. The interviews were conducted semi-structured and had the character of 'guided conversations' (Yin, 2003). The semi-open design was chosen in line with the study's intention to break new ground and gain valuable insights into the relationships of protection strategies and business models. Conducting semi-structured interviews allows for in-depth questions (as opposed to strict questionnaires, which cannot discover further details if they prove necessary), with the added flexibility of enabling the interviewer to shorten to detailed questions if no more knowledge of the expert's side can be reached. However, it still provides enough structure to ensure comparability between cases (Mack et al., 2005). The questions were sent to the interviewees in advance so that they could prepare appropriately. Next, we conducted the interviews (approximately 1.5-2 hours per interview). The interview guide included an introduction of the topic, the aim of the study, a mix of open and closed questions around their respective business model and which formal as well as informal IP strategies the firms applied to protect their business.

Second, we collected additional archival data, such as press releases, published documentations and presentations, which enhanced our understanding of the strategies the selected firms executed (Rowley, 2002).

Third, we visited the Swiss Federal Institute of Intellectual Property due to following reasons.

The one-day visit featured lectures from senior patent experts, as well as observation of their daily work - both of which provided deep insights into how Intellectual Property titles (e.g., patents, trademarks, designs, and business methods) are examined, granted and administered.

During that time, we held numerous informal conversations, took notes of our observations and wrote them down. We also received expert guidance while searching for IP titles that our relevant firms registered worldwide. The visit helped us to better understand the relationships of the registered titles to their business models - specifically, how these titles add to the protection of the firms' business models. Furthermore, by investigating patent disputes involving our case companies and the respective court decision, we were able to improve our understanding of protection strength of the various titles 
The data collection was supported by MBA students, who were trained in the topics of business models and IP management, and were accompanied and coached throughout the process (Zott and Amit, 2007; 2008).

As qualitative case study research is often biased we took several steps to maximise the trustworthiness of our study. In line with Lincoln and Guba (1985), we focused on three criteria: credibility, dependability and transferability. In terms of credibility, we tested the findings' fit with reality by comparing the interview results with the collected secondary data. In all cases we found a strong fit between what the interviewees said and what we found in other sources. 'triangulating' our findings (Jick, 1979) by using different data sources (interviews, informal conversations, observations, publically available documents and presentations) made us confident that we had attained the necessary credibility for our research goal. Dependability - the consistency of the findings - was achieved through focused interviews and the selection of interview partners who had deep insights into their business model. Finally, transferability - which corresponds to internal validity, reliability and external validity - was ensured by comparing our results with a broad set of previous findings in adjacent literature (Eisenhardt, 1989). We also increased transferability through including a variety of industries in our sample.

\subsection{Data analysis and rating matrix}

In order to analyse the collected qualitative data, we initially transcribed the recorded interviews verbatim (Corbin and Strauss, 2008) before writing case stories for each business model and firm. Next, we coded the data in two rounds. First, in line with our theory part, we build on the seven identified formal and informal IP protection mechanisms from Gallié and Legros (2012), namely patents, trademarks, designs, copyrights, trade-secrets, complexity of products or manufacturing processes, and leadtime advantage. Reading through the interviews and case stories allowed us to identify themes and topics that we assigned to the existing labels. Second, during the coding, additional themes emerged that did not fit the existing codes. One possible explanation for this comes from the fact that Gallié and Legros (2012), who offered the most comprehensive set of protecion mechanisms in past empirical studies, only tested these mechanisms only in the context of the community innovation survey (CIS4), which addresses only four innovation types. Specifically, these types were

a product (good or service) innovation

b innovation in the production or manufacturing processes of good or services (production-method innovation)

c innovation in the methods of logistics, supply or distribution of raw materials, goods or services

d innovation in support activities, such as maintenance, purchasing or accountancy.

The field of business model innovation was omitted. Therefore it is likely that the traditional IP instruments are not sufficient in fully explaining the protection of business models. As business models take a rather holistic view of the firm's business, it seems that further informal strategies that are not captured in the existing instruments are gaining importance. To address this problem, we created additional codes until we felt 
that we had achieved theoretical saturation (Glaser and Strauss, 1967), where the creation of additional codes would not lead to further theoretical refinement. In total, eight further codes were created, which were all characterised as informal IP instruments or complementary assets. We labelled them as strong brand, qualified employees, strong partner network, loyal customers, value chain control, strong distribution channels, superior pricing, and quasi monopolies (see upper right side of Table 2). Topics and themes that fitted the new codes were assigned accordingly. Through the coding we identified similarities across the cases and developed initial relationships between the constructs. We then iterated going back and forth between original data, initial findings, and literature until we achieved a coherent picture.

Following this process, for each firm we rated the extent to which they used each IP strategy for business model protection. Our rating system comprised a four-point scale anchored at 'not at all used' and 'strongly used'. The measure was rated by the first two authors independently for each of the 15 protection strategies and, for each of the 24 cases. In some cases, differences in ratings on the four-point type scale initially occurred..We resolved these differences by joint discussions and by re-examining the case data (Bullock, 1986). Such a rater approach is quite common in this type of research (Frankenberger et al., 2013; Keupp et al., 2012; Nag et al., 2007; Zott and Amit, 2007; 2008). Subsequently, we added the values for formal and informal protection strategies for each case to arrive at a case measure for the relevance of formal and informal protection strategies. Finally, we calculated the average of the values for each business model category to enable comparison across business models.

\section{Results}

Table 2 shows the results of our analysis. The crosses display the ratings for each protection strategy and for each case. Empty cells in the table stand for a ' 0 ' rating or no usage of the IP strategy and cells marked with $\mathrm{xxx}$ ' 3 ' stand for a strong usage of the IP strategy. The numbers show the calculated averages for the relevance of formal and informal protection strategies for each case and for each business model.

As shown in Table 2, all firms investigated take advantage of various protection instruments, which are of both types - formal and informal. Our results also show that cases operating the same business model show similar configurations of formal and informal protection mechanisms applied. Firms operating the razor and blade business model are characterised by the extensive use of formal as well as informal protection instruments displayed by high values in both categories: 10.8 for formal and 24.2 for informal protection. Franchising firms only partially make use of formal protection instruments (4.5) and pay more attention to informal instruments, such as qualified and motivated employees (21.6).

For firms that apply the pay-per-use business model, we observed a medium level of use for both informal (15) and formal protection (3.8) strategies. Similarly, firms who operate multi-sided platform business models show a medium degree of informal protection (12.3) and a medium degree of formal protection (5.2). Relying solely on formal protection strategies seems unattractive for all firms of our sample. 
Table 2 Overview of IP protection and rating matrix

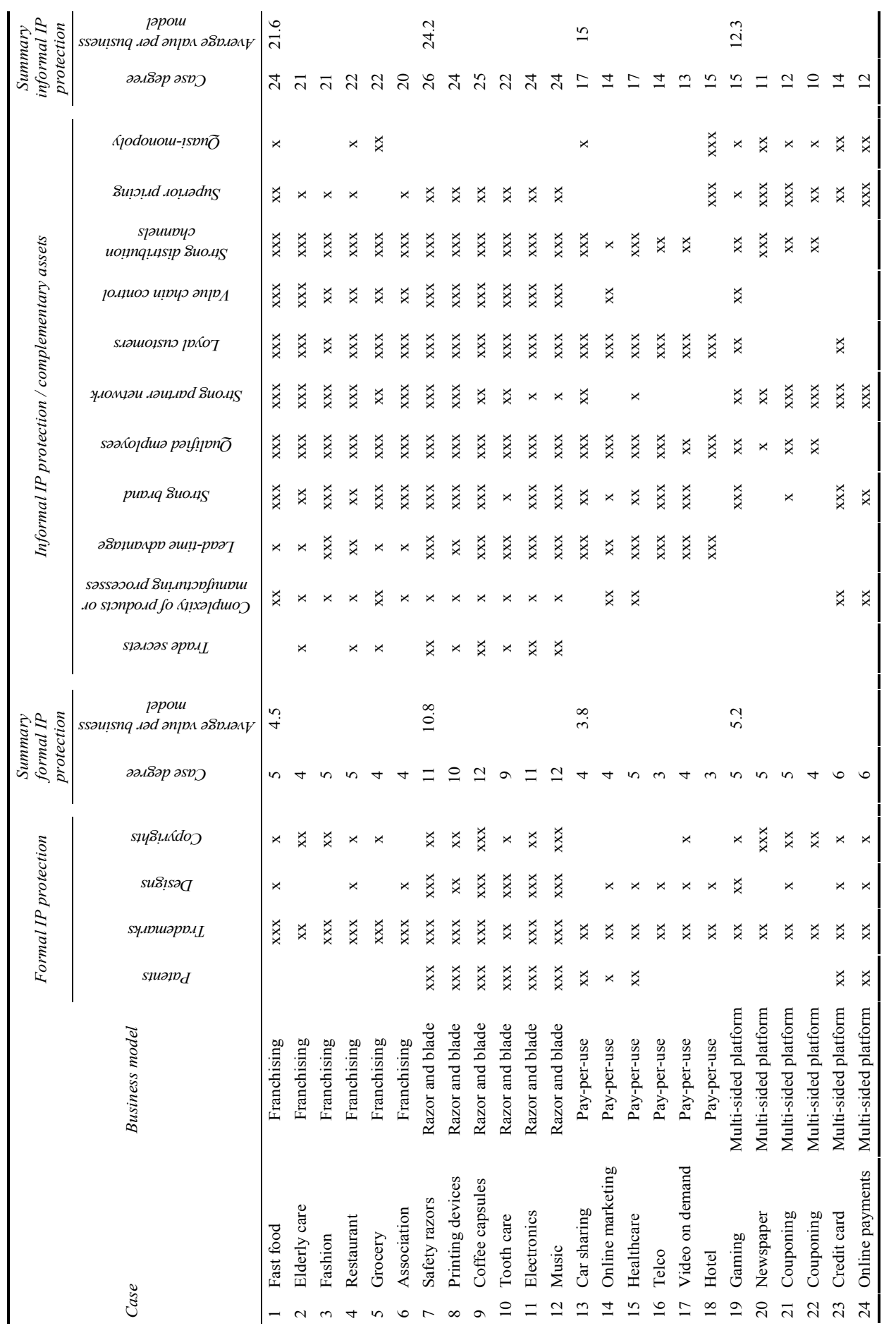


To better understand the results we developed a business model protection framework that allows identification of the level of formal and informal protection strategy required for each business model type in order to capture value. We chose a four field matrix to portray the firms' positions (Figure 1) and set the borders of the fields according to the averages across all cases. This enabled us to reveal the relative us (high or low) of formal and informal protection instruments. The levels 0 to 5 of the degree of formal protection are classified into the fields B and C, the levels 6 and higher to the fields of A and D. Correspondingly, the fields $\mathrm{C}$ and $\mathrm{D}$ include the levels 0 to 18 of the degree of informal protection, while the levels 19 and higher are represented by fields B an A. The four field matrix is portrayed in Figure 1.

Figure 1 Business model protection framework (see online version for colours)

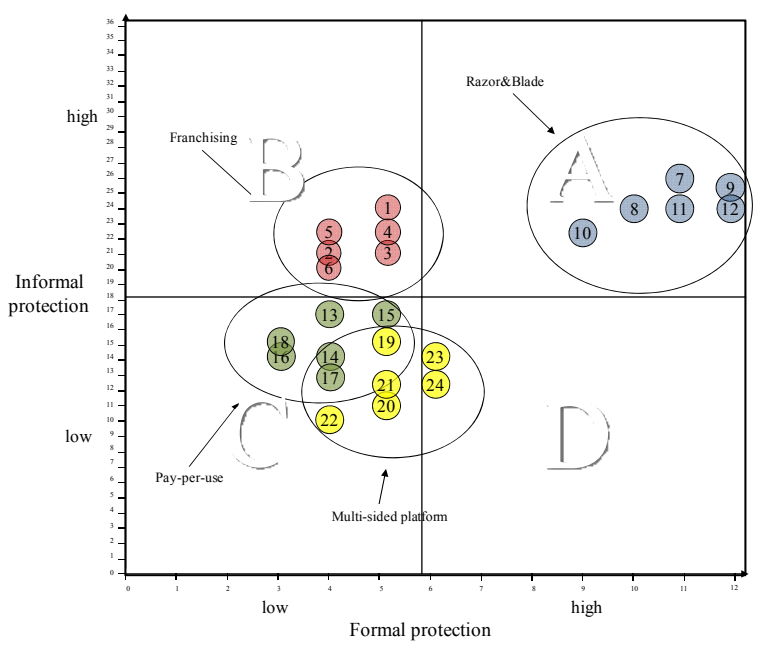

\subsection{Razor and blade and IP protection strategies}

Firms choosing a razor and blade model make high use of both formal and informal instruments. They are characterised by a very dominant and partially aggressive appearance on the market. For example the razor and blade manufacturer (case 7) continuously further develops its technologies and registers patents for any incremental progress in their technology, including all technical details of the blade, such as the composition of the strips, the positioning of the blades, and the angle of the razor blade touching the skin. It owns more than 13.000 patents, 5.130 of which in the category B26B21 ('razors of the open or knife type; Hair-trimming devices involving a razorblade') and 734 in the category B26B19 ('clippers or shavers operating with a plurality of cutting edges, e.g. hair clippers, dry shavers') (European Patent Office, 2012) - i.e., over half of all patents are related to razors and blades. Taking a closer look, more than 50 patents, several design rights, and trademarks are assigned only to one razor (Aoki, 2003).

However the razor and blade manufacturer does not only focus on formal protection mechanisms, as outlined in the following statement from one expert: "It is important, that [company name] continuously launches new, innovative, and better products, which replace the prior models before their patents expire." herefore, the razor and blade 
manufacturer also pays strong attention to informal protection mechanisms like 'pioneering' and invests heavily in R\&D as well as in consumer insights. An additional informal protection mechanism exists in the form of brand image. Being one of the world's most valuable brands (Interbrand, 2012), the firm's brand image gives men confidence that they can reach everything in life they want.

A second example for razor and blade business models is represented by the inkjet printer company (case 8), which owns more than 37.000 active patents and represents one of the largest patent portfolios worldwide (Swiss Federal Institute of IP, 2012). Like the prior firm, case 8 registered most of its patents to products related to the razor and blade business model - in its case the ink printer technologies. Informal protection instruments of case 8 comprise the loss of warranty of the printers in the case of refilling cartridges from third party providers as well as means to increase customer loyalty by integrating 'smart chips' into cartridges, which monitor the ink level and encourage the consumer to replace the cartridges prematurely before running out of ink.

The coffee machine and capsules manufacturer (case 9) uses formal protection instruments actively to keep competitors out of the market by prosecuting imitators of capsules aggressively. Case 9 also uses informal protection strategies such as the creation of a 'super premium brand' in order to increase customer loyalty. With its boutique shops and its highly trained employees as well as celebrity advertisement, case 9 delivers its customers the impression of being part of an exclusive club. Not only does this strategy enhance the business models lock-in effect, it also lowers the entry barriers for noncustomers.

In summary, we argue that firms adopting the razor and blade business model employ a high level of formal and informal IP strategies in order to capture the value of this business model:

Proposition 1 Razor and blade business models are characterised by the usage of a high level of formal and informal protection strategies to capture value.

\subsection{Franchising and IP protection strategies}

Business models, that follow the franchising model, focus primarily on informal protection strategies, only using formal protection strategies to a limited. The burger franchise chain (case 1) hardly makes use of patents, which is underlined by a quote from our case 1 informant: "We have the equipment and suppliers just as others may have, anyone could imitate the burgers. The competitors respect our experience. Everything has to come together at the right time and there is huge machinery behind." This statement is in line with the remaining franchising firms. They appear to focus on building informal protection and complementary assets instead of relying solely on patented products, processes or services. Indeed, most firms that apply a franchising business model, did mention that formal protection strategies are only important for their business model to protect their strong brands (informal protection) by the use of trademarks (formal protection). These statements reflect the logic of the franchising business model. Customers associate a certain quality of products or services with a brand. Therefore, building strong brands (informal protection) and protecting them by the use of trademarks (formal protection) helps franchisors to exploit their business idea faster and in different territories - through the franchisees - by attracting customers who rely on the same level of quality worldwide. 
Besides building a strong brand there are two additional informal protection strategies that seem to be of notable importance. First, strong distribution channels appeared to play a crucial role for capturing value from the franchising business model - primarily because most franchising firms operate in the retail sector and franchising products often are standardised and not technically sophisticated. For the grocery stores of case 9 the location as part of the distribution channel is most important. In the grocery industry the same or very similar products are available in different chains, which make grocery stores partially interchangeable. Therefore, spatial proximity plays an important role. As a result, case 9 tries to rent store space especially in high frequented places such as train stations, which adds quasi-monopoly advantages as our informant mentions: "As the case may be, also the renter mix is protected, that is not an infinite number of identical stores is allowed to be opened in one train station." The second informal protection strategy used by firms applying the franchising business model is illustrated by qualified employees. Qualified employees are an important differentiation feature - especially for firms who are not able to set themselves apart from the competition through high-tech products. Here, the service character of employees in the franchise stores receives much higher attention. This is why franchisees often have to go through a detailed selection process in order to receive licenses from the franchisors.

In the light of these findings, we argue that, for franchising business models, a high level of informal protection and a medium level of formal protection strategies leads to superior value capture. Formally:

Proposition 2 Franchising business models are characterised by the usage of a high level of informal and a medium level of formal protection strategies to capture value.

\subsection{Pay-per-use and IP protection strategies}

Firms pursuing a pay-per-use business model are characterised by a medium use of both formal and informal protection instruments.

The car sharing company (case 13) states that it is almost impossible to protect its business model. Their customers are usually also customers of competitors and viceversa, as outlined by in the following quote: "For car sharing customers it is only important to get to a vehicle as fast as possible and located as close as possible, it does not matter if it's one of ours or a competitor's one." As the car sharing concept is a very young and fast-growing concept it seems that the players on the market profit from each other, as they are currently complementing one another. If a customer signs up for one car sharing provider, the likelihood of registering at another provider in the same area rises, as the customer wants access to as many vehicles as possible in the region to stay mobile.

This makes protection difficult. But even for such 'open' and young business models, which are difficult to protect, we observed protection attempts by the respective firms. The car sharing company usually negotiates parking possibilities throughout the city with city representatives. It is important that customers can drop their cars off anywhere and do not have to drive to a specific station. Being the first provider to negotiate with city representatives opens up the advantage of receiving better prices for the parking spots and covering a broader area for parking spaces, since they are very limited downtown. Such a lead time advantage is an important informal protection strategy. The firm also 
applied a formal protection strategy: in order to open the cars of their fleet, customers need to implement a chip on their driving license. Holding the driving license against a sensor attached to the windshield will unlock the car. This chip technology is patented, but its protection power to keep competitors out of the market is limited, since various alternative technologies exist.

Another example of pay-per-use business models is represented by case 14, the search engine marketing company. Instead of paying a fixed (sometimes monthly) fee for an advertisement, case 14 offers invoicing only per amount of times the advertisement is clicked. This is an affordable way for firms to advertise in an efficient, customer specific manner. In order to protect the online advertisement industry's common pay-per-click approach, the firm follows two strategies. First, they build strategic partnerships with search engine firms, which offer them exclusive marketing rights on their platform. Second, their search algorithm, which matches demographical data with key words and raises the relevance of placing the ad, is patented. However, as it is very hard to prove process or algorithm infringements, this protection strategy's power is rather limited.

As pay-per-use business models are characterised by customers not paying any initial upfront costs and thereby do not carry out any upfront investments it is quite challenging for firms to protect their business model from competition. The prior mentioned examples of formal and informal protection mechanisms can be classified as having medium protection relevance. Summing up, we argue that firms protecting their pay-peruse business model employ a medium level of of both informal and formal strategies.

Proposition 3 Pay-per-use business models are characterised by the usage of a medium level of informal and a medium level of formal protection strategies to capture value.

\subsection{Multi-sided platform and IP protection strategies}

For firms that apply the multi-sided platform business model, we observed a medium level of use both for informal and formal protection strategies.

For example case 21 for example represents a firm that offers highly discounted coupons of retailers to end customers on its platform. Their attempt to protect their business model formally was carried out by patenting the method of 'communal purchasing', which protects the procedure to offer deals only if a certain number of buyers purchase it in a certain time frame. However, when we asked our case 21 informant why the firm was successful despite its business model being quite easy to imitate (even with the patent of 'communal purchasing') his answer was: "The main reason for our success was operational excellence as well as our very high speed." We observed that the couponing firm also focused on strong distribution channels and establishment of powerful sales teams. This allowed the firm to grow much faster and territorially wider than its competitors that also offered coupons online (albeit in a slightly different way to avoid infringement of the communal purchasing patent). Entering the market aggressively enabled the firm to generate a self-enforcing growth effect, which is typical for multi-sided platform business models. For multi-sided business models, gaining a critical mass of customers is more important than focusing solely on patents. We observed similar characteristics with the other cases in our multisided business model category. The credit card company (case 23) holds various patents that cover activities related to the operation of credit analyses, the issuance and the 
management of credit cards, the activation and verification of credit cards, the prediction of financial risk, and electronic payments - just to name a few. However, our case 23 informant also pointed out that "registering a patent is one thing, but enforcing it is something completely different." Given that most registered patents cover internal processes, it is quite challenging for the credit card company to observe and fight patent infringements. Similar to the statements of our informant from the couponing company the credit card company also attributes the success of their business model to their operational excellence. "Everyone wants to play in the payment space, until they realise the difficulties of getting the infrastructure in place". Performing handling details (e.g. charge backs, disputes etc.) conveniently plays a crucial role for the firm's success. That is why the credit card company also focuses on managing a strong partner network and operating complex processes smoothly.

Summing up, we argue that firms characterised by the multi-sided platform business model are recognised as using a medium level of both formal and informal protection.

Proposition 4 Multi-sided platform business models are characterised by the usage of a medium level of formal and a medium level of informal protection strategies to capture value.

\section{Conclusions and implications}

\subsection{Conclusions}

Our results reveal that the use of formal and informal protection strategies differ across various business models. The propositions and the business model protection framework show that depending on the business model the firm selects, different protection strategies are necessary to successfully protect the business model. Therefore, firms need to carefully think carefully about whether or not they can build up the protection strategies required for a particular business model before they attempt to adopt it..

\subsection{Theoretical implications}

Our study integrates intellectual property management insights with business model literature, thereby contributing to both research streams accordingly. Although previous scholars on business models have highlighted that business models need to create and capture value (Chesbrough, 2007; Johnson et al., 2008; Morris et al., 2005; Teece, 2010; Zott et al., 2011), research to date has focused mainly on value creation drivers and neglected to analyse how to capture value. The results of this study show that firms operating the same business model archetype exhibit similar patterns regarding the configuration of formal and informal protection instruments, whereas firms operating different business models exhibit different configurations of formal and informal protection strategies. The razor and blade business model is characterised by high use of formal as well as informal protection; the franchising business model is protected by a high level of informal protection and a medium level of formal protection instruments; and the pay-per-use model and the multi-sided platform model both adopt a medium level of formal and informal protection instruments. Thus, we extend initial research in the important field of IP protection for business models (Desyllas and Sako, 2013). 
We also enhance the 'profiting from innovation' literature (Amara et al., 2008; Arora and Ceccagnoli, 2006; Dosi et al., 2006; Hall and Ziedonis, 2001; Harabi, 1995; McGahan and Silverman, 2006; Pisano, 2006; Teece, 1986; 2006) by extending the applicability of IP protection mechanisms to the context of business models. Furthermore by using multiple protection strategies for formal and informal protection and moreover by adding additional informal protection strategies we extend research on IP strategies, which has thus far mainly focused on patents and secrecy as the two main protection strategies (Gallié and Legros, 2012).

Finally, we contribute to the current discussion on customer identification and engagement in the context of creating and capturing value from business models (Baden-Fuller and Mangematin, 2013; Teece, 2010). The study portrays four business models where customers' engagement is highly dependent on the use of particularly informal protection instruments. It reveals the following implications for per business model.

Razor and blade business models face the challenge to convince customers, usually consumers, to commit long-term to their business model, as customers are 'locked-in' after buying the basic device. The study implies that firms who run the razor and blade business model, need to put high emphasis on pioneering activities to integrate a tailor made consumable for the basic device they are selling. This allows them to create a unique experience that is superior to regular products and/or services. Additionally, enriching this technical experience with strong branding activities allows creating exclusivity, which in combination enables capturing premium prices.

When running franchising business models firms need to engage customers by promising and delivering the same level of product or service quality in all regions and countries the firms operate in. The study reveals, that it is equally important to engage customers by building strong brands to strengthen the value proposition and focusing on further informal protection instruments such as qualified employees and a strong partner and distribution networks for value delivery. Especially, franchisees have to be carefully selected and closely monitored throughout the entire business relationship to ensure delivering the promised standard and hence keeping customers satisfied.

Implications on customer engagement mechanisms for pay-per-use business models are generalisable only to a little extent and highly industry specific. Engaging in pay-peruse business models does not require high upfront investments (if any), which leads to low switching-costs. Hence, customers only engage, when receiving a high degree of convenience and efficiency to solve their needs. Firms from our case samples built strong partner and distribution networks to broaden their product and service offering and concentrated on high quality customer service (customer loyalty) to keep their business model protected.

Firms that operate with multisided-platform business models need to reach a critical mass of users from at least two distinct user groups as fast as possible, as the attractiveness of the platform increases with the number of users from each side. Informal protection strategies to achieve customer engagement play a very strong role. Most important for customers' engagement is operational excellence, which relies on a successful interplay of managing a large partner network, building strong distribution channels, and establishing powerful sales teams. The higher the network effects, the higher the switching costs for customers to switch on other platforms, that is the network 
effects create 'lock-ins' for customers and serve as a protection to keep customers engaged.

\subsection{Managerial implications}

The results of our study - namely, the different configurations as well as the different intensities in the use of formal and informal protection mechanisms, depending on which business model is operated - leads to the following managerial implications. First, the results can serve as a starting point for practitioners to achieve a thorough understanding of the relationship between business models and IP protections instruments. Second,, managers of incumbent firms who attempt to review their business model can use the matrix as a reference for how other successful companies apply formal and informal protection instruments, and also for how they capture value from their business model. Depending on the current business model they operate, it might be useful for enhancing certain protection instruments (e.g., by establishing the appropriate complementary assets) in order to generate competitive advantages.

Third, recent entrepreneurs can take the results as guidance for deciding which the business model they want to operate. Depending on their current assets, they might be more successful running a business model they can protect and consequently capture higher value from. On the other hand, the results could also help to allocate resources to where they are needed most. As young entrepreneurs typically have limited resources, they need to focus on protection instruments that are strategically most reasonable. We suggest that firms running the razor and blade business model establish both strong formal as well as informal protection. In contrast, for firms operating the franchising business model, it appears reasonable to focus on informal protection strategies such as building strong brands, strong distribution channels and paying attention to qualified employees. Finally, firms that run the pay-per-use and the multi-sided platform business model seem to use less protection than the other two models. They make medium use of formal as well as informal protection.

\subsection{Limitations and future research}

One limitation of our study is that our sample was limited to 24 cases, and covered only four business models. Larger studies that include more business models would enhance the explanatory power of the business model protection matrix. Furthermore, as our study is based on qualitative case study research, a quantitative study testing the identified propositions would mark a promising path for future research. A longitudinal study could also shed more light on the importance of formal and informal protection strategies during different phases of business model development. We hope our work contributes to the exciting topic of business models and IP management, and encourage future research in this field.

\section{References}

Amara, N., Landry, R. and Traoré, N. (2008) 'Managing the protection of innovations in knowledge intensive business services', Research Policy, Vol. 37, No. 9, pp.1530-1547.

Amit, R. and Zott, C. (2001) 'Value creation in e-business', Strategic Management Journal, Vol. 22, Nos. 6/7, p.493. 
Anton, J.J. and Yao, D.A. (2004) 'Little patents and big secrets: managing intellectual property', RAND Journal of Economics, Vol. 35, No. 1, pp.1-22.

Aoki, N. (2003) 'The war of the razors', The Boston Globe, 31 August [online] http://www.boston.com/business/globe/articles/2003/08/31/the_war_of_the_razors/ (accessed 11 December 2012).

Arora, A. and Ceccagnoli, M. (2006) 'Patent protection, complementary assets, and firms' incentives for technology licensing', Management Science, Vol. 52, No. 2, pp.293-308.

Arundel, A. (2001) 'The relative effectiveness of patents and secrecy for appropriation', Research Policy, Vol. 30, No. 4, pp.611-624.

Baden-Fuller, C. and Demil, B. and Lecoq, X. and MacMillan, I. (2010) 'Editorial', Long Range Planning, Vol. 43, Nos. 2-3, pp.143-145.

Baden-Fuller, C. and Mangematin, V. (2013) 'Business models: a challenging agenda', Strategic Organization, Vol. 11, No. 4, pp.418-427.

Baden-Fuller, C. and Morgan, M.S. (2010) 'Business models as models', Long Range Planning, Vol. 43, No. 2, pp.156-171.

Björkdahl, J. (2009) 'Technology cross-fertilization and the business model: the case of integrating ICTs in mechanical engineering products', Research Policy, Vol. 38, No. 9, pp.1468-1477.

Brickley, J.A. and Dark, F.H. (1987) 'The choice of organizational form the case of franchising', Journal of Financial Economics, Vol. 18, No. 2, pp.401-420.

Bullock, R.J. (1986) 'A meta-analysis method for OD case studies', Group \& Organization Management, Vol. 11, Nos. 1-2, pp.33-48.

Casadesus-Masanell, R. and Zhu, F. (2010) 'Strategies to fight ad-sponsored rivals', Management Science, Vol. 56, No. 9, pp.1484-1499.

Casadesus-Masanell, R. and Zhu, F. (2013) 'Business model innovation and competitive imitation: the case of sponsor-based business models', Strategic Management Journal, Vol. 34, No. 4, pp.464-482.

Caves, R.E. and Murphy, W.F. (1976) 'Franchising: firms, markets, and intangible assets', Southern Economic Journal, Vol. 42, No. 4, pp.572-586.

Chesbrough, H. (2007) 'Business model innovation: it's not just about technology anymore', Strategy \& Leadership, Vol. 35, No. 6, pp.12-17.

Chesbrough, H. and Rosenbloom, R.S. (2002) 'The role of the business model in capturing value from innovation: evidence from Xerox Corporation's technology spin-off companies', Industrial and Corporate Change, Vol. 11, No. 3, pp.529-555.

Chesbrough, H., Birkinshaw, J. and Teubal, M. (2006) 'Introduction to the research policy 20th anniversary special issue of the publication of 'profiting from innovation' by David J. Teece', Research Policy, Vol. 35, No. 8, pp.1091-1099.

Cohen, W.M., Nelson, R.R. and Walsh, J.P. (2000) Protecting their Intellectual Assets: Appropriability Conditions and Why US Manufacturing Firms Patent (or Not), No. w7552, National Bureau of Economic Research.

Corbin, J. and Strauss, A. (2008) Basics of Qualitative Research, 3rd ed., London, Sage.

DaSilva, C.M. and Trkman, P. (2014) 'Business model: what it is and what it is not', Long Range Planning, Vol. 47, No. 6, pp.379-389.

Demil, B. and Lecocq, X. (2010) 'Business model evolution: in search of dynamic consistency', Long Range Planning, Vol. 43, No. 2, pp.227-246.

Desyllas, P. and Sako, M. (2013) 'Profiting from business model innovation: evidence from pay-as-you-drive auto insurance', Research Policy, Vol. 42, No. 1, pp.101-116.

Doganova, L. and Eyquem-Renault, M. (2009) 'What do business models do?: Innovation devices in technology entrepreneurship', Research Policy, Vol. 38, No. 10, pp.1559-1570.

Dosi, G., Marengo, L. and Pasquali, C. (2006) 'How much should society fuel the greed of innovators?: On the relations between appropriability, opportunities and rates of innovation', Research Policy, Vol. 35, No. 8, pp.1110-1121. 
Eisenhardt, K.M. (1989) 'Building theories from case study research', Academy of Management Review, Vol. 14, No. 4, pp.532-550.

Eisenmann, T., Parker, G. and Van Alstyne, M.W. (2006) 'Strategies for two-sided markets', Harvard Business Review, Vol. 84, No. 10, p.92.

European Patent Office (2012) European Patent Office [online] http://worldwide.espacenet.com/ advancedSearch?locale=en_EP (accessed 13 November 2012).

Evans, D.S. (2003) 'Some empirical aspects of multi-sided platform industries', Review of Network Economics, Vol. 2, No. 3, pp.191-209.

Frankenberger, K., Weiblen, T. and Gassmann, O. (2013) 'Network configuration, customer centricity, and performance of open business models: a solution provider perspective', Industrial Marketing Management, Vol. 42, No. 5, pp.671-682.

Gallié, E.P. and Legros, D. (2012) 'French firms' strategies for protecting their intellectual property', Research Policy, Vol. 41, No. 4, pp.780-794.

Glaser, B. and Strauss, A. (1967) The Discovery of Grounded Theory, Weidenfeld and Nicholson, London.

Hagiu, A. (2009) Multi-sided Platforms: From Microfoundations to Design and Expansion Strategies, Harvard Business School Strategy Unit Working paper 09-115.

Hall, B.H. and Ziedonis, R.H. (2001) 'The patent paradox revisited: an empirical study of patenting in the US semiconductor industry, 1979-1995', RAND Journal of Economics, Vol. 32, No. 1, pp.101-128.

Harabi, N. (1995) 'Appropriability of technical innovations an empirical analysis', Research Policy, Vol. 24, No. 6, pp.981-992.

Hussinger, K. (2006) 'Is silence golden? Patents versus secrecy at the firm level', Economics of Innovation and New Technology, Vol. 15, No. 8, pp.735-752.

Interbrand (2012) Best Global Brand 2012 [online] http://www.interbrand.com/de/best-globalbrands/2012/Best-Global-Brands-2012-Brand-View.aspx (accessed 13 November 2012).

Jiang, B., Chen, P.Y. and Mukhopadhyay, T. (2007) Software Licensing: Pay-Per-Use Versus Perpetual, available at SSRN 1088570.

Jick, T.D. (1979) 'Mixing qualitative and quantitative methods: Triangulation in action', Administrative Science Quarterly, Vol. 24, No. 9, pp.602-611.

Johnson, M.W. (2010) Seizing the White Space: Business Model Innovation for Growth and Renewal, Harvard Business Press, Boston.

Johnson, M.W., Christensen, C.M. and Kagermann, H. (2008) 'Reinventing your business model', Harvard Business Review, Vol. 86, No. 12, pp.57-68.

Keupp, M.M., Palmié, M. and Gassmann, O. (2012) 'The strategic management of innovation: a systematic review and paths for future research', International Journal of Management Reviews, Vol. 14, No. 4, pp.367-390.

Kim, S. (2005) 'The pay-per-use revolution in the internet world', Online Information Review, Vol. 29, No. 4, pp.419-421.

Klang, D., Wallnöfer, M. and Hacklin, F. (2014) 'The business model paradox: a systematic review and exploration of antecedents', International Journal of Management Reviews, Vol. 16, No. 4, pp.454-478.

Lafontaine, F. (1992) 'Agency theory and franchising: some empirical results', The Rand Journal of Economics, Vol. 23, No. 2, pp.263-283.

Lepak, D.P., Smith, K.G. and Taylor, M.S. (2007) 'Value creation and value capture: a multilevel perspective', Academy of Management Review, Vol. 32, No. 1, pp.180-194.

Lincoln, Y.S. and Guba, E.G. (1985) Naturalist Inquiry, Sage, Beverly Hills, CA.

Mack, N., Woodsong, C., MacQueen, K.M., Guest, G. and Namey, E. (2005) Qualitative Research Methods: A Data Collectors Field Guide, Family Health International, Durham. 
Magretta, J. (2002) 'Why business models matter', Harvard Business Review, Vol. 80, No. 5, pp.86-93.

McGahan, A.M. and Silverman, B.S. (2006) 'Profiting from technological innovation by others: the effect of competitor patenting on firm value', Research Policy, Vol. 35, No. 8, pp.1222-1242.

McGrath, R.G. (2010) 'Business models: a discovery driven approach', Long Range Planning, Vol. 43, No. 2, pp.247-261.

Miles, M.B. and Huberman, A.M. (1994) Qualitative Data Analysis: An Expanded Sourcebook, Sage, Thousand Oaks; London; New Delhi.

Morris, M., Schindehutte, M. and Allen, J. (2005) 'The entrepreneur's business model: toward a unified perspective', Journal of Business Research, Vol. 58, No. 6, pp.726-735.

Nag, R., Hambrick, D.C. and Chen, M.J. (2007) 'What is strategic management, really? Inductive derivation of a consensus definition of the field', Strategic Management Journal, Vol. 28, No. 9, pp.935-955.

Norton, S.W. (1988) 'An empirical look at franchising as an organizational form', Journal of Business, Vol. 61, No. 2, pp.197-218.

Patton, M.Q. (1987) How to Use Qualitative Methods in Evaluation, No. 4, Sage, Newbury Park.

Pisano, G. (2006) 'Profiting from innovation and the intellectual property revolution', Research Policy, Vol. 35, No. 8, pp.1122-1130.

Postmus, D., Wijngaard, J. and Wortmann, H. (2009) 'An economic model to compare the profitability of pay-per-use and fixed-fee licensing', Information and Software Technology, Vol. 51, No. 3, pp.581-588.

Priem, R.L. (2007) 'A consumer perspective on value creation', Academy of Management Review, Vol. 32, No. 1, pp.219-235.

Rappa, M. (2001) Managing the Digital Enterprise-Business Models on the Web [online] http://www.digitalenterprise.org/models/models.html (accessed 1 December 2012).

Rivette, K.G. and Kline, D. (2000) 'Discovering new value in intellectual property', Harvard Business Review, Vol. 79, No. 1, pp.54-66.

Rochet, J.C. and Tirole, J. (2003) 'Platform competition in two-sided markets', Journal of the European Economic Association, pp.990-1029.

Rowley, J. (2002) 'Using case studies in research', Management Research News, Vol. 25, No. 1, pp.16-27.

Shafer, S.M., Smith, H.J. and Linder, J.C. (2005) 'The power of business models', Business Horizons, Vol. 48, No. 3, pp.199-207.

Swiss Federal Institute of IP (2012) Interview Swiss Federal Institute of IP, Bern.

Teece, D.J. (1986) 'Profiting from technological innovation: implications for integration, collaboration, licensing and public policy', Research Policy, Vol. 15, No. 6, pp.285-305.

Teece, D.J. (2006) 'Reflections on "profiting from innovation"', Research Policy, Vol. 35, No. 8, pp.1131-1146.

Teece, D.J. (2010) 'Business models, business strategy and innovation', Long Range Planning, Vol. 43, No. 2, pp.172-194.

Yin, R.K. (2003) Case Study Research Design and Methods, 3rd ed., Vol. 5, Sage, Thousand Oaks.

Zott, C. and Amit, R. (2007) 'Business model design and the performance of entrepreneurial firms', Organization Science, Vol. 18, No. 2, pp.181-199.

Zott, C. and Amit, R. (2008) 'The fit between product market strategy and business model: implications for firm performance', Strategic Management Journal, Vol. 29, No. 1, pp.1-26.

Zott, C. and Amit, R. (2013) 'The business model: a theoretically anchored robust construct for strategic analysis', Strategic Organization, Vol. 11, No. 4, pp.403-411.

Zott, C., Amit, R. and Massa, L. (2011) 'The business model: recent developments and future research', Journal of Management, Vol. 37, No. 4, pp.1019-1042. 